\title{
Correction to: Development of a Fuzzy Multi-Objective Heuristic Model for Optimum Water Allocation
}

\section{Mohammad Ebrahim Banihabib ${ }^{1}$ • Mahmoud Mohammad Rezapour Tabari ${ }^{2}$. Mohsen Mohammad Rezapour Tabari ${ }^{3}$}

Received: 26 April 2017 / Accepted: 12 July 2019 /

Published online: 11 December 2019

(C) Springer Nature B.V. 2019

\section{Correction to: Water Resour Manag \\ https://doi.org/10.1007/s11269-019-02323-7}

The original version of this article unfortunately contains mistakes introduced during the publishing process. The mistakes and corrections are described in the following list:

1) Affiliation 1 and 3, "Tehran University" should be "University of Tehran".

2) Affiliation 2, there is a mistype as "Departmentt" instead of Department.

Publisher's Note Springer Nature remains neutral with regard to jurisdictional claims in published maps and institutional affiliations.

The online version of the original article can be found at https://oi.org/10.1007/s11269-019-02323-7

Mohammad Ebrahim Banihabib

banihabib@ut.ac.ir

1 Department of Irrigation and Drainage Engineering, University of Tehran, Tehran, Iran

2 Department of Engineering, University of Mazandaran, Babolsar, Mazandaran, Iran

3 Department of Irrigation and Drainage Engineering, University of Tehran, Tehran, Iran 